\title{
Correction to: Textbook of Sports and Exercise Cardiology
}

Axel Pressler and Josef Niebauer

\section{Correction to: A. Pressler, J. Niebauer (eds.), Textbook of Sports and Exercise Cardiology, https://doi.org/10.1007/978-3-030-35374-2}

The original version of the chapter 5 and chapter 26 is revised as follows,

In Chapter 5, Figure 5.1 data has been corrected.

Initially the chapter 26 was published with the co-author name as Eric Solberg.

Now chapter 26 and List of contributors, Table of contents in the Front matter was updated with the Author's full name as Erik Ekker Solberg.

The updated online version of this book can be found at https://doi.org/10.1007/978-3-030-35374-2 

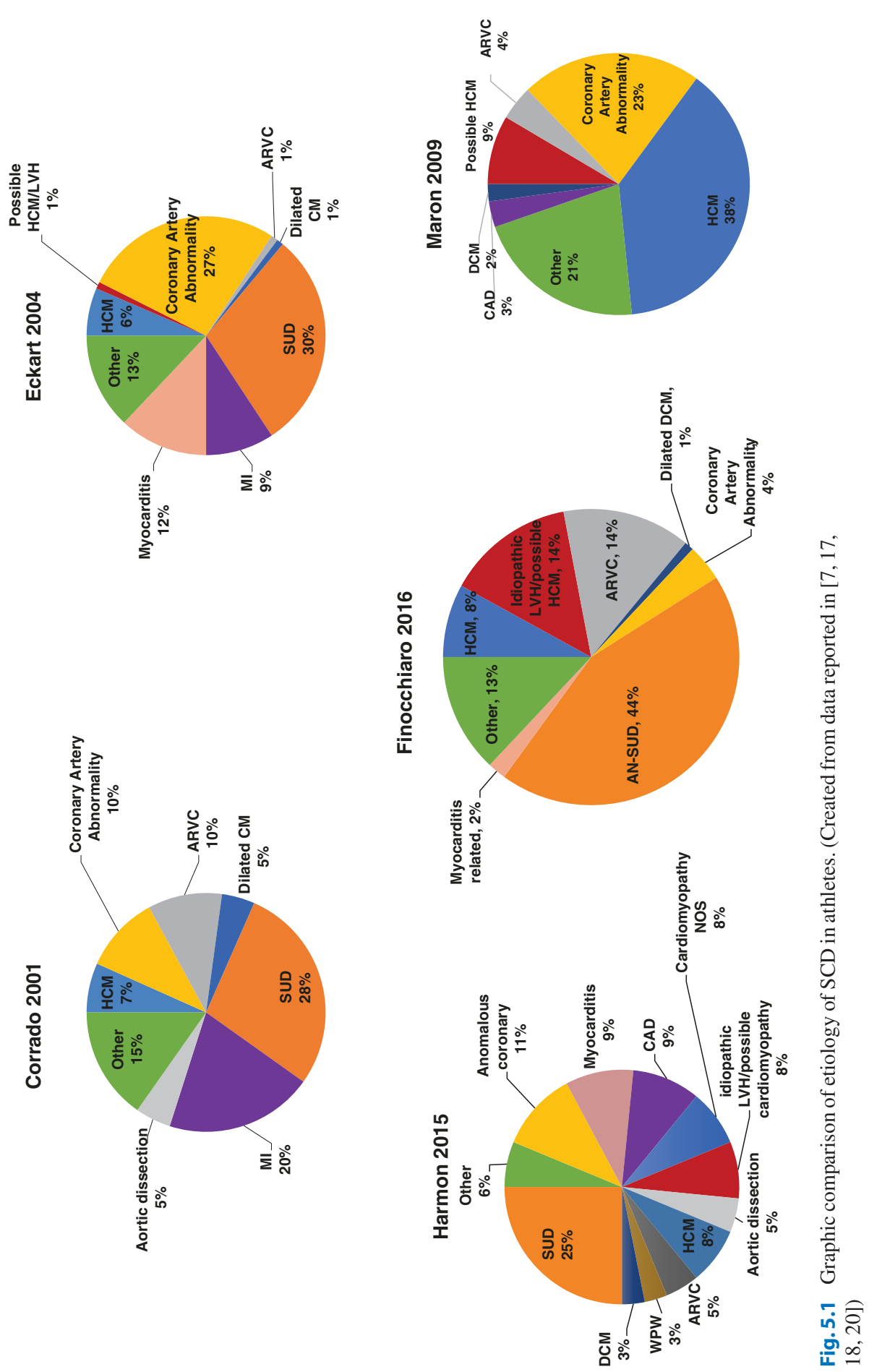